\title{
Nutrient Release Pattern of a Fortified Manure Disc and its Implication on Yield of Tomato in Sandy Soils
}

\author{
V. Mini, G. Suja
}

10.18805/IJARe.A-5778

\begin{abstract}
Background: Development of fortified organic formulations using various organic sources and fertilizers for soil application will ensure efficient nutrient management in homestead vegetable production systems. Fortified organic formulations will help in preventing nutrient leaching also. Hence, the present study has been undertaken during 2019-20 to develop low cost fortified organic manure discs using various biodegradable agro waste materials and NPK fertilizers and to study its effect on growth and yield of tomato in sandy soils of Kerala.

Methods: A fortified manure disc was developed by combining local biodegradable agro waste materials with conventional NPK fertilizers. Organic manures like rice husk ash, cow dung, rice husk, coirpith compost, vermicompost, neem cake and clay were used to develop the manure disc. The combination of organic manures was fortified with fertilizers at various proportions of manure: fertilizer viz., 1:1, 2:1, 0.5:1 and manure alone and used for incubation for a period of two months to study the nutrient release pattern of $\mathrm{N}, \mathrm{P}$ and $\mathrm{K}$. The 2:1 (manure: fertilizer) formulation was selected based on the highest peak of nutrient availability of $\mathrm{N}, \mathrm{P}$ and $\mathrm{K}$ even after 2 months. Effect of fortified manure disc was evaluated by using tomato variety Anagha as test crop in a pot culture experiment. Result: Growth, yield and quality of tomato increased significantly due to the application of fortified manure disc. The highest yield per plant of $0.97 \mathrm{~kg}$ was recorded for T8 (50\% recommended dose fortified manure disc in $2 \mathrm{splits})$ and lowest yield was recorded for T9 (Manure alone). The fortified manure disc had a significant influence on nutrient use efficiency also. The highest NUE of $45.5 \%$ was recorded in treatment T8 (50\% fertilizer fortified discs in 2 splits). Study revealed that fortified manure disc is a promising technology to reduce nutrient leaching and enhancing the nutrient use efficiency in sandy soils. Fifty percentage reduction in the recommended dose of NPK fertilizers were achieved by fortifying the manure disc with fertilizers. Thus the cost of fertilizers and fertilizer load per unit area can be reduced by the application of fortified manure disc which will act as slow release fertilizer.
\end{abstract}

Key words: Fortified manure disc, Nutrient release, Tomato, Sandy soil, Yield.

\section{INTRODUCTION}

Surface runoff and leaching loss contribute to the loss of major share of applied fertilizers in sandy soils and to reduce the nutrient losses, the efficiency of chemical fertilizers has to be improved. Use of chemical fertilizers in conjunction with organic manures improves the fertilizer use efficiency in sandy soils (Nair et al., 2013). Most of the commercially available fortified organic manures are costly and so it is not easily accessible by Indian farmers. There is a need for establishing new ways for improving crop yields while avoiding environmental pollution and soil degradation using cost-effective and locally available organic inputs (Tellen and Mbiseh, 2020). Supplementing the organic inputs with various sources of fortifiers is more environmentally friendly than opting for chemical sources alone (Hammed et al., 2020). In this context a fortified manure disc developed out of locally available materials are relevant to develop a low cost, sustainable, ecofriendly fortified fertilizer. Moreover, nowadays people prefer cultivation of vegetable crops with minimum use of fertilizers and homestead vegetable cultivation in grow bags and pots are getting more popular and balanced nutrient management in this type of cultivation is a problem (Mini, 2015). A ready to use user friendly and ecofriendly organic input formulation encompassing essential nutrients will decrease the difficulty in nutrient
Onattukara Regional Agricultural Research Station, Kerala Agricultural University, Kayamkulam-690 502, Kerala, India.

Corresponding Author: V. Mini, Onattukara Regional Agricultural Research Station, Kerala Agricultural University, Kayamkulam-690 502, Kerala, India. Email: minisvilas@gmail.com

How to cite this article: Mini, V. and Suja, G. (2021). Nutrient Release Pattern of a Fortified Manure Disc and its Implication on Yield of Tomato in Sandy Soils. Indian Journal of Agricultural Research. DOI: 10.18805/IJARe.A-5778.

Submitted: 26-03-2021 Accepted: 24-06-2021

Online: $02-08-2021$

management in grow bags and pots. Development of fortified organic formulations using various organic sources and fertilizers for soil application will ensure efficient nutrient management in homestead vegetable production systems. Fortified organic formulations will help in preventing nutrient leaching also (Mini and Adithya, 2021). Hence the present study has been undertaken to develop low cost fortified organic manure discs using various biodegradable agro waste materials like rice husk ash, clay, cow dung, rice husk, coir pith compost, vermicompost and neem cake and NPK fertilizers. The nutrient release pattern from this fortified manure disc was studied and its implications on yield and quality of tomato were assessed. 


\section{MATERIALS AND METHODS}

A study on development and evaluation of a fortified manure disc for increasing nutrient use efficiency in sandy soil was carried out during 2019-20 at Onattukara Regional Agricultural Research Station, Kayamkulam in the sandy soils of Onattukara Sandy plain of Kerala, India. A fortified manure disc was developed by combining organic manures with conventional NPK fertilizers. For developing the manure disc, various biodegradable agro waste materials viz., rice husk ash, clay, cow dung, rice husk, coir pith compost, vermicompost and neemcake were collected separately, oven dried and powdered in a grinder. The collected agro waste materials were characterized and nutrient composition was determined using the standard analytical procedures (Jackson, 1973). The powdered materials were combined in 1:1:0.5:0.5:0.5:0.5:0.5 combination (Adithya and Mini, 2019) to form organic manure disc. Organic manure disc with 1:1:0.5:0.5:0.5:0.5:0.5 proportions was fortified with recommended dose of $\mathrm{N}: \mathrm{P}: \mathrm{K}$ as per Package of Practices (KAU, 2014). An incubation study was conducted using fortified manure discs of $0.5: 1,1: 1$ and 2: 1, manure: fertilizer combinations and manure alone to study the nutrient release pattern and changes in various soil properties at 15 days interval up to two months. The treatments were $\mathrm{T} 1$ 1:1 disc, T2- 2:1 disc, T3- 0.5:1 disc and T4 - manure alone disc. Effect of fortified manure disc on nutrient use efficiency was evaluated by using tomato variety Anagha as test crop in a pot culture experiment.

\section{RESULTS AND DISCUSSION}

\section{Release pattern of nitrogen}

Fortified manure disc containing manure: fertilizer in the ratio of $2: 1$ gave the maximum release at the $60^{\text {th }}$ day of sampling (Fig 1), thus this combination was selected as the best for slow release of nitrogen due to the ability to retain their release even after 2 month of incubation. The release pattern of nitrogen from fortified organic manure disc revealed that the relative rate of release of $\mathrm{N}$ is slower and are capable of retaining the availability for a long period of time by reducing the leaching and runoff losses of nitrogen in the soil (Tolescu and lovu, 2010).

\section{Release pattern of phosphorus}

Phosphorus release was increasing up to 45 days after incubation and later it decreased for all treatments (Fig 2). The highest value was observed on $45^{\text {th }}$ day after incubation for all treatments and among which the highest value was shown by $2: 1$ fortified disc. Phosphorus is essential for the initial growth and establishment of the crop. Here also $P$ release is more in the initial period of incubation which will help in crop growth. In acidic soil generally phosphorus availability is affected by $P$ fixation in the soil. The organic manure could also act as an electrostatic barrier to obstruct the fixation of phosphate ions in soil (Wang et al., 2011). The entrapment of rock phosphate in the organic manure will gradually release the $P$ into the soil, which will reduce the fixation and increase the availability for longer period of time.

\section{Release pattern of potassium}

Potassium release from fortified manure disc showed a gradually increasing pattern (Fig 3 ) up to $60^{\text {th }}$ day of incubation. The 2:1 fortified disc recorded highest release rate in the $60^{\text {th }}$ day of incubation. The highest release peak was seen in $60^{\text {th }}$ day of incubation in all the treatments and hence the potassium availability will be synchronizing with the crop requirement during fruit setting and developing stage. The treatment with manure disc alone also recorded considerable amount of $\mathrm{K}$ availability which showed that the manure disc itself contributed $K$ to the soil. The slow mineralization of potassium from the rice husk ash may be the reason for the increasing trend of potassium from the

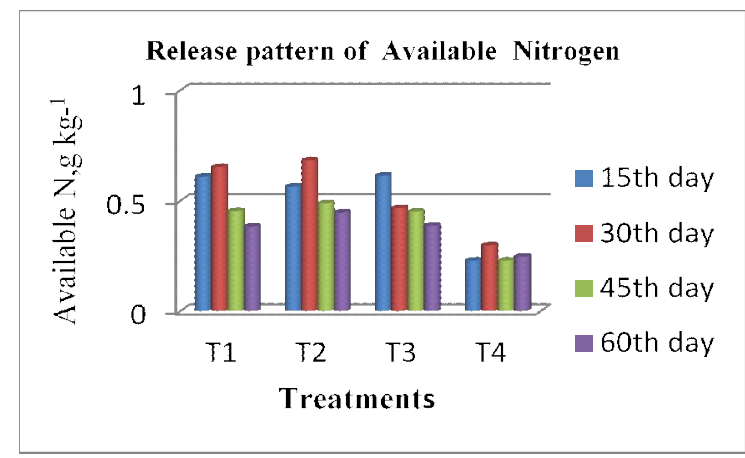

Fig 1: Release pattern of available $n$.

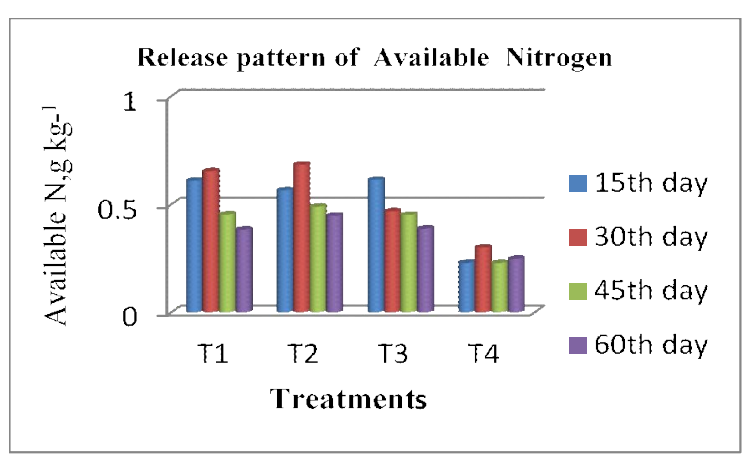

Fig 2: Release pattern of available $P$.

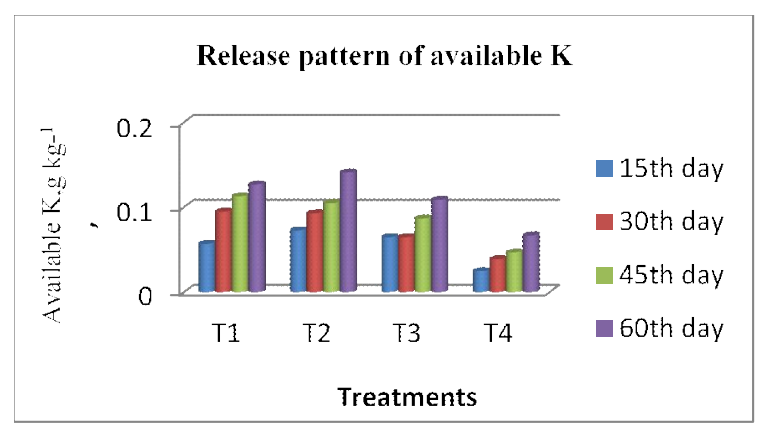

Fig 3: Release pattern of available K. 
fortified manure disc. Priyadharshini and Seran (2009) reported that potassium fertilizers can be substituted by rice husk ash as a source of potassium.

\section{Effect of fortified manure disc on yield and nutrient use efficiency}

Based on the data on nutrient release pattern from the incubation study, the 2:1 disc formulation was selected for fortifying with NPK fertilizers for the pot culture experiment and it was also fortified with secondary and micronutrient mixture $(0.03 \%)$ for vegetables developed for sandy soils (Mini and Mathew, 2016). Fortified manure disc of $100 \mathrm{~g}$ was applied per pot and in the case of split application $50 \mathrm{~g}$ disc was applied as basal and another $50 \mathrm{~g}$ disc was applied 30 days after first application. Fortified manure disc application had significant influence on yield per plant. The highest yield per plant of $0.97 \mathrm{~kg}$ (Table 1) was recorded for T8 (50\% fertilizer fortified discs in 2 splits) and it was at par with T2 in which $100 \%$ recommended dose of fertilizer as per POP was applied. T8 was at par with T4 and T6 also indicating that $50 \%$ recommended dose of fertilizer is sufficient in the fortified form. The lowest yield was recorded for T9 $(0.48 \mathrm{~kg}$ per plant). Fifty percentage reduction in the recommended dose of fertilizer was achieved by this fortified manure disc application. This is due to the reduced leaching loss of nutrients from the fortified manure disc and it acted as a slow release fertilizer. Organic matrix entrapped urea and DAP containing $1 / 4^{\text {th }}$ of the recommended dose of urea and DAP produced wheat biomass and grain yield almost equal to that obtained with full recommended dose of soluble urea and DAP. Entrapment of commercially available conventional urea in the organic matrix significantly increased the efficacy of urea for wheat production (Kumar et al., 2013). Singh et al. (2017) reported that the double and triple dose of biofertilizers in entrapped form gave the same concentration of alkaloid content as that of single dose. This might be due to the proper nutrient enrichment in accordance with the crop requirement from the single dose itself due to reduced leaching and increased plant uptake.

The fortified manure disc had a significant influence on nutrient use efficiency also. The highest NUE of $45.5 \%$ was recorded in treatment T8. The NUE of POP was calculated as $19.4 \%$ (Table 1). The main limiting factor in nutrient management in sandy soil is high nutrient leaching, which is responsible for the low NUE. Slow release fertilizers can contribute to enhance the NUE and minimize environmental hazards (Trenkel, 2010). The treatment T8 (50\% fertilizer fortified discs in 2 splits) recorded the highest value for nutrient use efficiency and yield. This might be due to the reduced leaching loss of nutrients from the fortified manure disc due to their entrapment in the organic matrix and increased plant uptake. Organic matrix in the fortified manure disc was capable of holding nutrients tightly as compared to soluble chemical fertilizers and increased the

Table 1: Effect of matrix based slow release fertilizers on yield and nutrient use efficiency in tomato.

\begin{tabular}{|c|c|c|c|}
\hline Treatment & No. of fruits plant ${ }^{-1}$ & Yield (kg plant $\left.{ }^{-1}\right)$ & Nutrient use efficiency (\%) \\
\hline $\mathrm{T}_{1}$ - POP- Basal & 31.0 & 0.80 & 13.3 \\
\hline $\mathrm{T}_{2}-{ }^{*} \mathrm{POP}-2$ split & 33.7 & 0.90 & 19.4 \\
\hline $\mathrm{T}_{3}-100 \%$ Fertilizer fortified disc - basal & 31.3 & 0.76 & 14.0 \\
\hline$T_{4}-100 \%$ Fertilizer fortified disc - 2 split & 33.1 & 0.84 & 17.3 \\
\hline $\mathrm{T}_{5}-75 \%$ Fertilizer fortified disc - basal & 32.3 & 0.78 & 18.2 \\
\hline $\mathrm{T}_{6}-75 \%$ Fertilizer fortified disc -2 split & 34.0 & 0.87 & 25.3 \\
\hline $\mathrm{T}_{7}-50 \%$ fertilizer fortified disc - basal & 32.0 & 0.83 & 30.6 \\
\hline $\mathrm{T}_{8}-50 \%$ fertilizer fortified disc -2 split & 35.3 & 0.97 & 45.5 \\
\hline T9- manure alone disc & 24.0 & 0.48 & \\
\hline$C D(0.05)$ & 1.873 & 0.130 & \\
\hline
\end{tabular}

* POP- Recommended dose of NPK (KAU, 2014).

Table 2: Effect of fortified manure disc on quality and nutrient content of the fruit in tomato.

\begin{tabular}{|c|c|c|c|c|c|}
\hline \multirow{2}{*}{ Treatment } & \multirow{2}{*}{$\begin{array}{r}\text { TSS } \\
(\%)\end{array}$} & \multirow{2}{*}{$\begin{array}{l}\text { Ascorbic acid } \\
\left({\left.\mathrm{mg} 100 \mathrm{~g}^{-1}\right)}\right.\end{array}$} & \multicolumn{3}{|c|}{ Nutrient content (\%) } \\
\hline & & & $\mathrm{N}$ & $\mathrm{P}$ & $\mathrm{K}$ \\
\hline $\mathrm{T}_{1}$-POP- Basal & 4.00 & 20.3 & 3.18 & 0.421 & 1.54 \\
\hline $\mathrm{T}_{2}{ }^{-{ }^{*} \mathrm{POP}-2 \text { split }}$ & 4.63 & 22.0 & 3.26 & 0.438 & 1.68 \\
\hline $\mathrm{T}_{3}-100 \%$ Fertilizer fortified disc - basal & 3.67 & 18.7 & 3.16 & 0.437 & 2.12 \\
\hline $\mathrm{T}_{4}-100 \%$ Fertilizer fortified disc -2 split & 4.67 & 21.7 & 3.48 & 0.465 & 2.12 \\
\hline $\mathrm{T}_{5}-75 \%$ Fertilizer fortified disc - basal & 3.67 & 20.0 & 3.27 & 0.434 & 1.66 \\
\hline $\mathrm{T}_{6}-75 \%$ Fertilizer fortified disc -2 split & 4.7 & 22.0 & 3.59 & 0.528 & 2.17 \\
\hline $\mathrm{T}_{7}-50 \%$ fertilizer fortified disc - basal & 3.17 & 18.0 & 3.16 & 0.415 & 2.20 \\
\hline $\mathrm{T}_{8}-50 \%$ fertilizer fortified disc -2 split & 5.33 & 22.3 & 3.69 & 0.555 & 2.20 \\
\hline T9- manure alone disc & 3.33 & 22.0 & 2.80 & 0.398 & 1.38 \\
\hline CD (0.05) & 0.746 & 1.675 & 0.245 & 0.105 & 0.333 \\
\hline
\end{tabular}


nutrient use efficiency significantly. Organic matrix contains cow dung, rice husk and clay which retain ammonium for longer duration and neem act as a nitrification inhibitor (Verkaik et al., 2006). Swain et al. (2013) reported that vermicompost based NPK fertilizers supplied higher nutrient content as compared to $100 \%$ NPK fertilizer application and $100 \%$ vermicompost application.

Fortified manure disc acted as a slow release organic matrix entrapped fertilizer. Slow release fertilizers release nutrients in harmony with the nutritional requirements of plants, thereby enhancing the fertilizer use efficiency, ensuring the reduction in the cost of fertilizers and increasing the productivity of crop (Azeem et al., 2014). Wu et al. (2018) reported that the low cost sustainable slow release organic matrix based urea fertilizer could increase the agronomic and apparent recovery efficiencies as compared to unentrapped conventional urea in wheat. This might be due to the reduced nitrogen loss (leaching and ammonia emission) and prolonged availability of nitrogen contributing to increased plant uptake. Singh et al. (2012) reported that the use of OMEU (Organic matrix entrapped urea) in rice increased \% OC, total NPK in plant, available $\mathrm{N}, \mathrm{P}$ and $\mathrm{K}$ in soil and increased the grain yield of rice by 3.6 fold and productivity by 32 percentage. It might be due to the agro waste materials that helped in increasing the organic matter content and nutrients in the soil.

\section{Effect of fortified manure disc on quality and nutrient content of the fruit}

The fortified manure disc had significant influence on quality parameters like TSS (\%) and Ascorbic acid content. The treatment T8 recorded the highest value for TSS (5.33\%) and ascorbic acid content (22.3 mg $100 \mathrm{~g}^{-1}$ ) (Table 2). Potassium supply determines the quality of fruits and hence the improvement in fruit quality may be due to the slow mineralization of potassium from the rice husk ash and enhanced availability of potassium from the fortified disc at the critical stage of fruit development. Valencia (2003) reported that the slow release nitrogen fertilizer with $\mathrm{K}$ source had significant effect in TSS ( ${ }^{\circ}$ Brix) in tomato.

The $50 \%$ recommended dose of NPK fertilizer in fortified disc form in two split (T8) recorded the highest values for $\mathrm{N}$ $(2.14 \%), P(0.538 \%)$ and $\mathrm{K}(2.62 \%)$ content in fruit (Table 2$)$ and it was at par with T2, T4 and T6 (Table 2). It was due to the enhanced nutrient use efficiency of N,P and K in these treatments. This may be due to the enhanced supply of nutrients and their translocation in plants by entrapping the inorganic sources in organic matrix based systems and their split application in sandy loam soils. Youmbi et al. (2009) reported that organo- mineral treatment have a tendency to give the highest fruit concentration of $\mathrm{P}$ and $\mathrm{K}$.

\section{CONCLUSION}

From the present study it was revealed that fortified organic manure disc is a promising technology to reduce nutrient leaching and enhancing the nutrient use efficiency in sandy soils. These fortified organic manure discs were capable of enhancing the growth, yield and quality of tomato. Fifty percentage reduction in the recommended dose of NPK fertilizers were achieved by entrapping these fertilizers in manure disc prepared from low cost agro waste materials. These fortified manure discs were capable of holding nutrients tightly as compared to soluble chemical fertilizers and increased the nutrient use efficiency significantly. Since all the materials used for the manure disc preparation are easily available, the technology can be popularized as a low cost technology for the production of slow release fertilizers for sandy soils. Thus the cost of fertilizers and fertilizer load per unit area can be reduced by the application of fortified organic manure based slow release fertilizers. Prolonged nutrient supplying capacity of this fortified manure discs can be effectively utilized for cultivation of crops in grow bags and pots.

\section{REFERENCES}

Adithya, G.R. and Mini, V. (2019). Effect of organic matrix based fertiliser on growth and yield of tomato on onattukara sandy soil. Green Farming. 10(5): 609-611.

Azeem, B., Kushaari, K., Man, Z.B., Basit, A. and Thanh, T.H. (2014). Review on materials and methods to produce controlled release coated urea fertilizer. Journal of Controlled Release. 181: 11-21.

Hammed, T.B., Ana, G.R.E.E. and Oloruntoba, E.O. (2020). Formulation of Natural Fortifiers from Readily Available Materials for Nutrient Enrichment of Organic Fertilizers. Environment and Natural Resources Journal. 18(1): 9-20.

Jackson, M.L. (1973). Soil Chemical Analysis. $2^{\text {nd }}$ Edn. Prentic Hall of India, New Delhi, 498p.

KAU [Kerala Agricultural University]. (2014). Package of Practices Recommendations: Crops (1 $5^{\text {th }}$ Ed.), Kerala Agricultural University, Thrissur, 360p.

Kumar, M., Bauddh, K., Kumar, S., Sainger, M., Sainger, P.A. and Singh, R.P. (2013). Increase in growth, productivity and nutritional status of wheat (Triticum aestivum L. Cv. WH711) and enrichment in soil fertility applied with organic matrix entrapped urea. Journal of Environmental Biology. 34(1): $1-8$.

Mini, V. (2015). Assessment and management of micronutrient deficiencies in Onattukara. Ph.D. thesis, Kerala Agricultural University, Thrissur, 246p.

Mini, V. and Adithya, G.R. (2021). Development of a customized organic matrix based fertilizer for increasing nutrient use efficiency. In: Food and Agriculture. Epublications. pp. 199-207.

Mini, V. and Mathew, U. (2016). Effect of customized nutrient mixture on yield of okra in Onattukara sandy plain. International Journal of Environment Agriculture and Biotechnology. 1(3): 531-534.

Nair, K.M., Saifudeen, N. and Suresh Kumar, P. (2013). Fertility of soils of Kerala.In: Soil fertility assessment and information management for enhancing crop productivity in Kerala. Kerala State Planning Board, pp.136-139. 
Priyadharshini, J. and Seran, T.H. (2009). Paddy husk ash, as a source of potassium for growth and yield of cowpea. Journal of Agricultural Science. 4(2): 67-76.

Singh, R.P., Bauddh, K., Sainger, M., Sainger, P.A., Singh, J.S. and Kumar, M. (2012). Increase in growth, productivity an nutritional status of rice (Oryza sativa L. cv. Basmati) and enrichment in soil fertility applied with an organic matrix entrapped urea. Journal of Crop Science and Biotechnology. 15(2): 137-144.

Singh, R.P., Kumar, S., Rai, A., Bauddh, K. and Singh, N. (2017). Improvement in growth and alkaloid content of Rauwolfia serpentina on application of organic matrix entrapped biofertilizers (Azotobacter chroococcum, Azospirillum brasilense and Pseudomonas putida). Journal of Plant Nutrition. 40(16): 2237-2247.

Swain, D.K., Murmu, K. and Ghosh, B.C. (2013). Comparative assessment of conventional and organic nutrient management on crop growth and yield and soil fertility in tomato-sweet corn production system. Australian Journal of Crop Science. 7(11): 1617.

Tellen, V.A. and Mbiseh, S. (2020). Effectiveness of Fortified Liquid Organic Manure and Inorganic Fertilizer on the Growth, Physiological and Pesticidal Response of African Nightshade (Solanum scabrum). Journa Agriculturand Ecology Research International. 21(7): 30-46.
Tolescu, C. and lovu, H. (2010). Polymer conditioned fertilizers. UPB Scientific Bullettin. 72(2): 3-14.

Trenkel, M.E. (2010). Slow-and controlled-release and stabilized fertilizers: an option for enhancing nutrient use efficiency in agriculture. International Fertilizer Industry Association, Paris, France. pp. 123.

Valencia, J. (2003). Effect of fertilizers on fruit quality of processing tomatoes. Acta Horticulturae. 613: 89-93.

Verkaik, E., Jongkind A.G. and Berendse, F. (2006). Short-term and long-term effects of tannins on nitrogen mineralization and litter decomposition in kauri [Agathis australis (D. Don) Lindl.] forests. Plant and Soil. 287: 337-339.

Wang, S., Alva, A.K., Li, Y. and Zhang, M. (2011). A rapid technique for prediction of nutrient release from polymer coated controlled release fertilizers. Open Journal of Soil Science. 1(2): 40.

Wu, Y., Liu, B., Yu, L., Zhou, Z., Ni, X., Tao, L. and Yang, Y. (2018). Nitrogen loss and rice profits with matrix- based slowrelease urea. Nutrient Cycling in Agroecosystems. 110(2): 213-225.

Youmbi, E., Tonfack, L.B., Bernadac, A., Mbouapouognigni, V.P., Ngueguim, M. and Akoa, A. (2009). Impact of organic and inorganic fertilizers on tomato vigor, yield and fruit composition under tropical andosol soil conditions. Fruits. 64(3): 167-177. 